\title{
Effect of sampling and diagnostic effort on the assessment of schistosomiasis and soil-transmitted helminthiasis and drug efficacy: a meta-analysis of six drug efficacy trials and one epidemiological survey
}

\author{
BRUNO LEVECKE ${ }^{1}$, SIMON J. BROOKER ${ }^{2}$, STEFANIE KNOPP ${ }^{3,4,5}$, \\ PETER STEINMANN ${ }^{4,5}$, JOSE CARLOS SOUSA-FIGUEIREDO ${ }^{6}$, \\ J. RUSSELL STOTHARD ${ }^{7}$, JÜRG UTZINGER ${ }^{4,5}$ and JOZEF VERCRUYSSE ${ }^{1}$ \\ ${ }^{1}$ Department of Virology, Parasitology and Immunology, Faculty of Veterinary Medicine, Ghent University, Salisburylaan \\ 133, 9820 Merelbeke, Belgium \\ ${ }^{2}$ Department of Disease Control, London School of Hygiene \& Tropical Medicine, Keppel Street, London WC1E 7HT, UK \\ ${ }^{3}$ Wolfson Wellcome Biomedical Laboratories, Department of Life Sciences, Natural History Museum, Cromwell Road, \\ London $S W 75 B D, U K$ \\ ${ }^{4}$ Department of Epidemiology and Public Health, Swiss Tropical and Public Health Institute, Socinstrasse 57, CH-4002 \\ Basel, Switzerland \\ ${ }^{5}$ University of Basel, Petersplatz 1, CH-4003 Basel, Switzerland \\ ${ }^{6}$ Department of Infectious and Tropical Diseases, London School of Hygiene छ Tropical Medicine, Keppel Street, London \\ WC1E $6 H T, U K$ \\ ${ }^{7}$ Department of Parasitology, Liverpool School of Tropical Medicine, Liverpool L3 5QA, UK
}

(Received 28 October 2013; revised 6 December 2013; accepted 6 December 2013; first published online 14 April 2014)

SUMMARY

It is generally recommended to perform multiple stool examinations in order to improve the diagnostic accuracy when assessing the impact of mass drug administration programmes to control human intestinal worm infections and determining efficacy of the drugs administered. However, the collection and diagnostic work-up of multiple stool samples increases costs and workload. It has been hypothesized that these increased efforts provide more accurate results when infection and drug efficacy are summarized by prevalence (proportion of subjects infected) and cure rate (CR, proportion of infected subjects that become egg-negative after drug administration), respectively, but not when these indicators are expressed in terms of infection intensity and egg reduction rate (ERR). We performed a meta-analysis of six drug efficacy trials and one epidemiological survey. We compared prevalence and intensity of infection, CR and ERR based on collection of one or two stool samples that were processed with single or duplicate Kato-Katz thick smears. We found that the accuracy of prevalence estimates and CR was lowest with the minimal sampling effort, but that this was not the case for estimating infection intensity and ERR. Hence, a single Kato-Katz thick smear is sufficient for reporting infection intensity and ERR following drug treatment.

Key words: Kato-Katz technique, Schistosoma mansoni, soil-transmitted helminths, sampling effort, diagnostic effort, prevalence, faecal egg counts, cure rate, egg reduction rate.

\section{INTRODUCTION}

After many years of apparent neglect, there is growing attention to the prevention, control and ultimate elimination of neglected tropical diseases (NTDs) (Hotez et al. 2007; WHO, 2010; NTD Partner Website, 2012; Utzinger et al. 2012). The global strategy for the control of NTDs due to helminth infections (e.g. lymphatic filariasis, onchocerciasis, schistosomiasis and soil-transmitted helminthiasis) is preventive chemotherapy (PC) whereby anthelmintic drugs are administered to at-risk populations,

* Corresponding author: Department of Virology, Parasitology and Immunology, Faculty of Veterinary Medicine, Ghent University, Salisburylaan 133, 9820 Merelbeke, Belgium. E-mail: Bruno.Levecke@UGent.be usually without prior diagnosis (WHO, 2006, 2010, 2011). Although this strategy reduces the immediate need for an accurate diagnosis at the individual level, considerable progress has been made in recent years in innovating, validating and applying novel diagnostic tools and strategies at the community level (Cringoli et al. 2010; Knopp et al. 2012; Colley et al. 2013; Mekonnen et al. 2013). Indeed, the topic of diagnosis is now a firm priority on the research agenda pertaining to the control and elimination of helminthiases (Bergquist et al. 2009; McCarthy et al. 2012; Rollinson et al. 2013).

The current standard means to diagnose Schistosoma mansoni and common soil-transmitted helminth (STH) infections (Ascaris lumbricoides, hookworm (Necator americanus and Ancylostoma 
duodenale) and Trichuris trichiura) is to demonstrate parasite eggs in stool samples using the Kato-Katz technique (Katz et al. 1972; WHO, 1991). However, the diagnosis of these helminths is complicated by variations in day-to-day egg excretion, the heterogeneous distribution of the eggs within stool samples and the relatively low diagnostic sensitivity of a single Kato-Katz thick smear due to the limited amount of faecal material examined (41.7 mg) (Sinniah, 1982; Engels et al. 1996, 1997; Ye et al. 1997; Krauth et al. 2012). To overcome these inherent shortcomings of the Kato-Katz technique, increased sampling and diagnostic efforts have been suggested as a way to improve the diagnostic sensitivity and accuracy. To increase the sampling effort, one can examine several samples per subject, collected over consecutive days (Booth et al. 2003; Knopp et al. 2008). To increase the diagnostic effort one can either examine multiple Kato-Katz thick smears per stool sample, use a diagnostic technique that allows examining a larger amount of stool such as the FLOTAC technique (up to $1 \mathrm{~g}$ ) (Knopp et al. 2009; Cringoli et al. 2010) or combine the test results of different diagnostic techniques (Glinz et al. 2010; Jeandron et al. 2010).

Both efforts increase technical, financial and human resources requirements, potentially leading to a non-optimal use of funds allocated for PC (Levecke et al. 2009; Speich et al. 2010), and hence making them less feasible to implement in resourceconstrained settings in which large-scale helminthiases PC programmes typically operate. However, it remains unclear whether these efforts are indeed required as the effect of stool sampling and diagnostic efforts may depend on the metric applied to summarize helminth infection and the efficacy of the drugs administered.

Helminth infection and drug efficacy can be summarized either qualitatively or quantitatively. Qualitative metrics are based on the absence or presence of helminth eggs in stool, and result in prevalence and cure rate (CR) estimates, respectively, whereas quantitative metrics are based on the enumeration of helminth eggs in stool, and include infection intensity measured by faecal egg counts (FECs) and egg reduction rate (ERR) estimates, respectively. Although increased sampling and diagnostic efforts will increase diagnostic sensitivity, and hence result in more accurate estimates of prevalence and CR (Knopp et al. 2011; Utzinger et al. 2011), it remains unclear whether this increased accuracy also translates into improved FECs and ERR estimates. Recent studies in both veterinary and human public health suggest that FECs and ERR are less influenced by diagnostic sensitivity. For example, in cattle, comparable FECs and ERR estimates were obtained by two techniques differing in diagnostic sensitivity (McMaster vs FLOTAC) (Levecke et al. 2011, 2012). Three studies comparing drug efficacy results against human STH infection between techniques (duplicate Kato-Katz thick smears $v s$ single FLOTAC (Knopp et al. 2011); single McMaster vs single Kato-Katz thick smear (Albonico et al. 2012); and triplicate Kato-Katz thick smears vs triplicate McMaster vs single FLOTAC (Albonico et al. 2013)) also indicated that significant differences in diagnostic sensitivity between techniques may not always translate into significant differences in ERR results. These findings, however, are contrary to the reported differences in FECs of human STH between Kato-Katz thick smear and FLOTAC (higher FECs using Kato-Katz thick smear compared with FLOTAC) (Utzinger et al. 2008; Cringoli et al. 2010; Knopp et al. 2011; Albonico et al. 2013).

There is ongoing debate whether prevalence and $\mathrm{CR}$ are appropriate metrics to monitor the long-term impact of helminthiases control programmes, as opposed to infection intensity and ERR, respectively (Humphries et al. 2011; Montresor, 2011; Montresor et al. 2011). Anderson and colleagues highlighted that a drop in FEC may not always be reflected in a drop in prevalence, leading to an under-estimation of the impact of control interventions (Anderson et al. 2012). Analogously, a drug may fail to cure helminth infections $(\mathrm{CR}=0 \%)$ but result in an ERR of $99 \%$, which is satisfactory. Additionally, Vercruysse and colleagues highlighted that drug efficacy, summarized as $\mathrm{CR}$, increases in function of decreasing FECs at baseline (Vercruysse et al. 2011). As a result, comparisons between populations differing in FEC at baseline are biased to provide different conclusions about drug efficacy. Although the aforementioned arguments suggest that an increase in both stool sampling and diagnostic effort may not be required as long as helminth infection and drug efficacy are characterized by quantitative metrics, there is a paucity of studies supporting this hypothesis.

In our present study, we investigated to what extent published helminth infection and drug efficacy results, as summarized by qualitative and quantitative measures, vary across different stool sampling and diagnostic effort scenarios. To this end, we performed a meta-analysis on available data of six clinical drug efficacy trials targeting $S$. mansoni $(n=4)$ and STH infection $(n=2)$ to compare prevalence, FEC, $\mathrm{CR}$ and ERR results obtained by analysing duplicate Kato-Katz thick smears on two consecutive stool samples $(2 \times 2 \mathrm{KK})$ with data from a single KatoKatz thick smear on one stool sample $(1 \times 1 \mathrm{KK})$, a duplicate Kato-Katz thick smear on one stool sample $(1 \times 2 \mathrm{KK})$ and a single Kato-Katz thicksmear on two consecutive stool samples $(2 \times 1 \mathrm{KK})$. In addition, we assessed whether the effect of diagnostic effort on the assessment of helminth infection changes over the level of endemicity. For this, we performed a meta-analysis on available data 


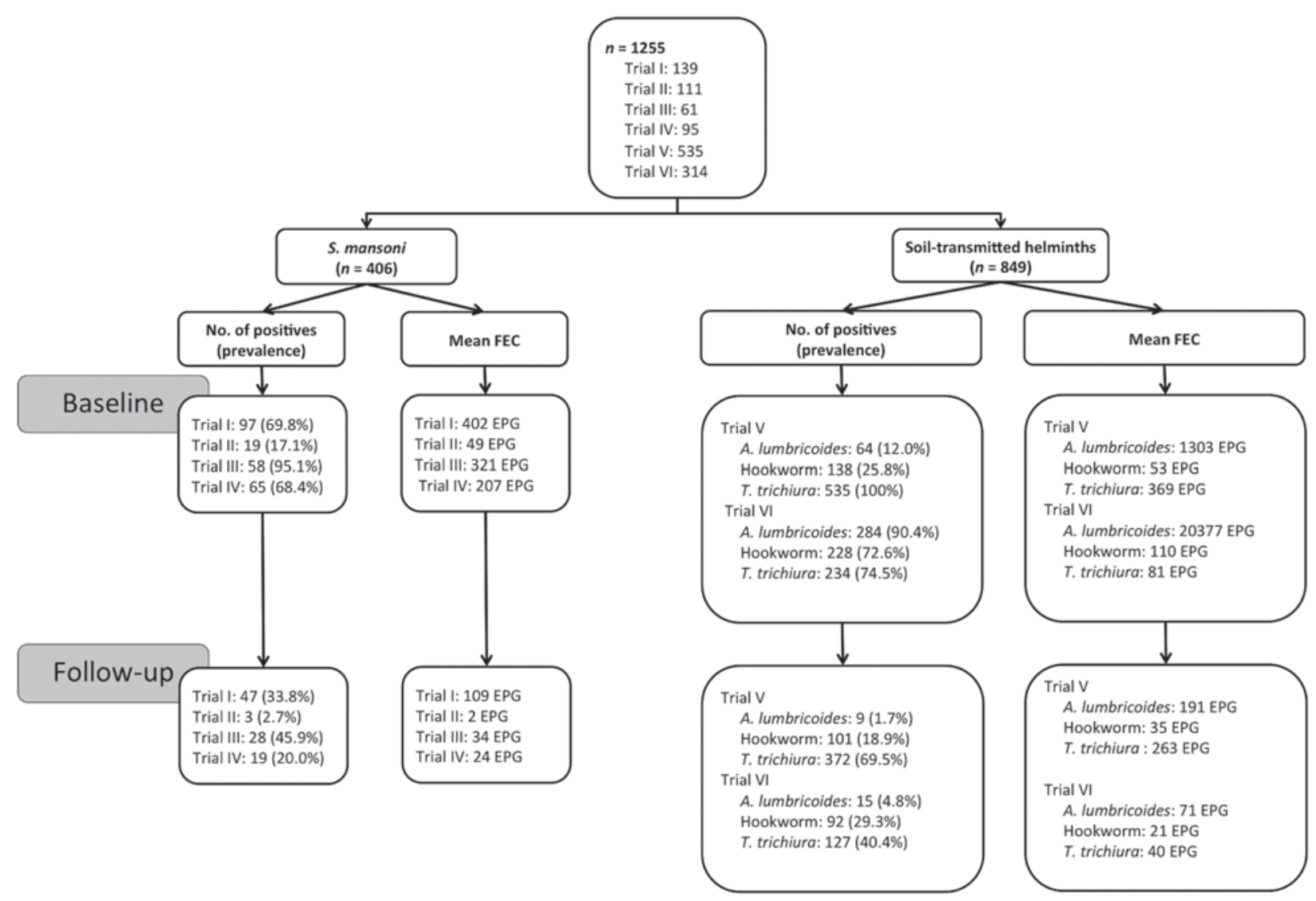

Fig. 1. Sample size, prevalence and faecal egg counts (FECs) of helminth infections assessed in six drug efficacy trials. The number of schoolchildren, the prevalence and FECs are based on duplicate Kato-Katz thick smears from two consecutive stool samples, both at baseline and treatment follow-up in six drug efficacy trials conducted in Uganda, Unguja island (United Republic of Tanzania) and the People's Republic of China.

of one epidemiological survey to compare prevalence and FEC results obtained by analysing $1 \times 2 \mathrm{KK}$ with data from $1 \times 1 \mathrm{KK}$ across three levels of endemicity of S. mansoni and STH infections.

\section{MATERIALS AND METHODS}

\section{Available data}

Drug efficacy trials. In our analyses we used data on six drug efficacy trials (trials I-VI) conducted in different geographical settings, including four targeting S. mansoni (trials I-IV) and two targeting STH infections (trials $\mathrm{V}$ and VI). The four trials aimed at $S$. mansoni were designed to assess anthelmintic drug efficacy of praziquantel (PZQ) in Uganda (trials I-IV). The two trials targeting STH infection assessed the efficacy of albendazole (ALB) and mebendazole (MEB) alone or in combination with ivermectin (IVM) in Zanzibar (trial V), and singledose $v$ s triple-dose of ALB and MEB in the People's Republic of China (trial VI). For further details of these drug intervention trials, including field and laboratory procedures, the reader is referred to Sousa-Figueiredo et al. (2012) (trials I-III), Knopp et al. (2010) (trial V) and Steinmann et al. (2011) (trial VI). The results of trial IV are not yet published.
In each trial, the sampling and diagnostic efforts were maximized by examining duplicate Kato-Katz thick smears from each of two consecutive stool samples, at both baseline and treatment follow-up, resulting in eight Kato-Katz thick smears per subject. The number of subjects for whom complete datasets were available, the prevalence and mean FECs both at baseline and treatment follow-up for each of the six trials are summarized in Fig. 1.

Epidemiological survey. The epidemiological survey included in our analyses was conducted in three countries in East Africa (Ethiopia, Kenya and Uganda). The main objective of this survey was to investigate the distribution and heterogeneity of coinfection with Plasmodium falciparum and helminth species, including S. mansoni and the three STH species. The presence and intensity of these helminth infections were determined by examination of one stool sample per child with duplicate Kato-Katz thick smears. Brooker et al. (2012) describes this epidemiological survey in more detail. We reanalysed the data obtained in Kenya. This dataset has been made publicly available at http://www. thiswormyworld.org and comprises of 17871 children across 178 schools (median number of children 


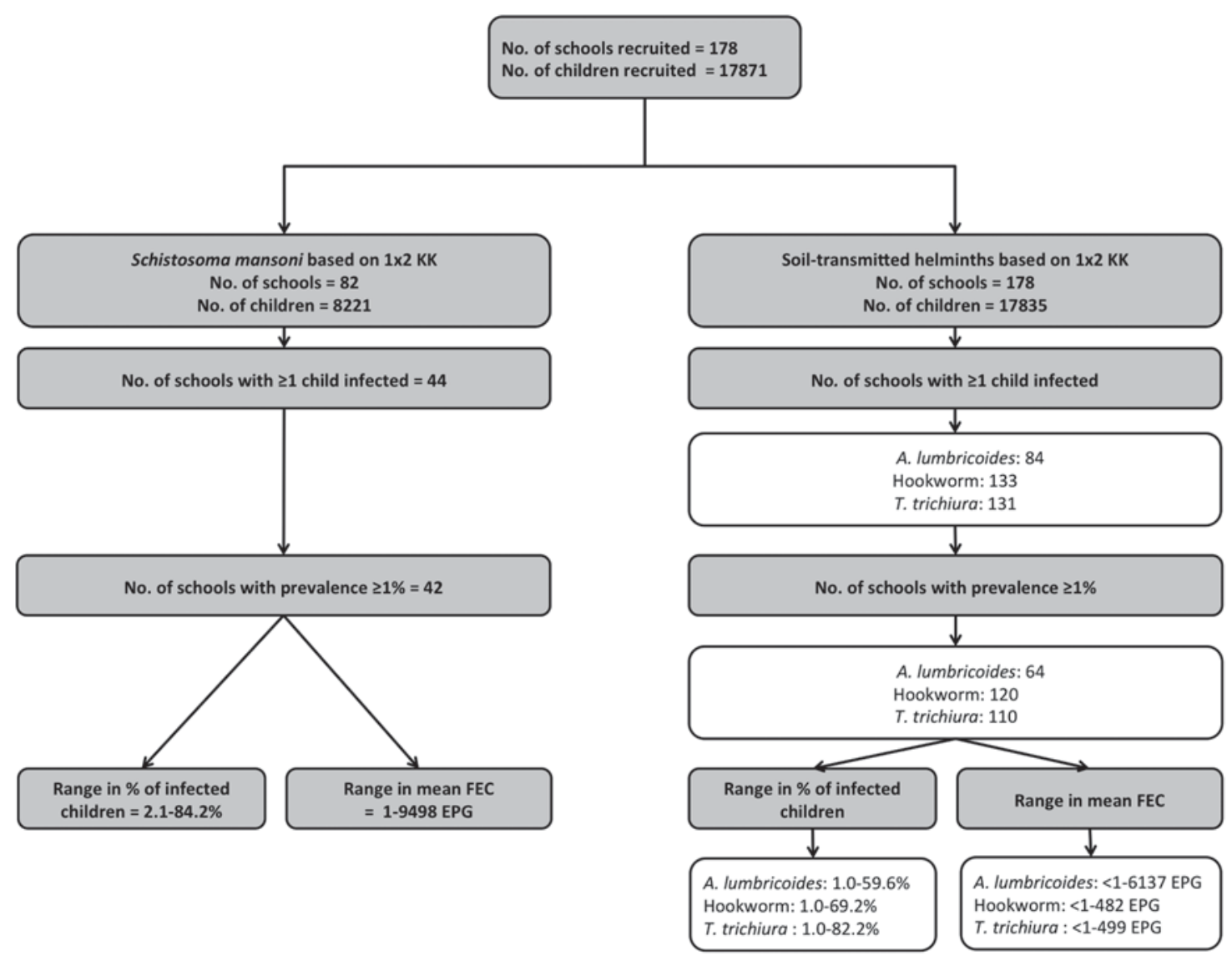

Fig. 2. Sample size, prevalence and faecal egg counts (FECs) of helminth infections assessed in 178 schools in Kenya. The number of children and schools, and the prevalence and FECs are based on duplicate Kato-Katz thick smears from one stool sample $(1 \times 2 \mathrm{KK})$.

per school; $n=104)$. Figure 2 summarizes the number of children and schools, and the ranges of prevalence and FEC based on duplicate Kato-Katz thick smears across these schools for each of the four helminth species separately.

\section{Statistical analysis}

Assessment of helminth infection and drug efficacy. First, we performed a meta-analysis to compare prevalence and FEC results according to duplicate Kato-Katz thick smears on two consecutive stool samples $(2 \times 2 \mathrm{KK})$ with those after a single KatoKatz thick smear on one stool sample $(1 \times 1 \mathrm{KK})$, duplicate Kato-Katz thick smears on one sample $(1 \times 2 \mathrm{KK})$ and a single Kato-Katz thick smear on two consecutive stool samples $(2 \times 1 \mathrm{KK})$. To this end, differences in prevalence and FECs were calculated for each of the three pairwise comparisons $(1 \times 1 \mathrm{KK}$ vs $2 \times 2 \mathrm{KK} ; 1 \times 2 \mathrm{KK}$ vs $2 \times 2 \mathrm{KK}$; and $2 \times 1 \mathrm{KK}$ vs $2 \times 2 \mathrm{KK}$ ) across the six trials (trials I-VI), two time points (baseline and treatment follow-up) and four helminth species (S. mansoni, A. lumbricoides, hookworm and $T$. trichiura), resulting in 48 estimates for $S$. mansoni infections ( 2 metrics $\times 3$ comparisons $\times$ 4 trials $\times 2$ time points), and 72 for $\mathrm{STH}$ infections
( 2 metrics $\times 3$ comparisons $\times 2$ trials $\times 2$ time points $\times$ 3 helminth species).

A 95\% confidence interval (CI) taking into account the correlation between the results was calculated for each estimate. For difference in prevalence results, the corresponding 95\% CI was determined by a bootstrap analysis (10000 iterations), as there is no standard formula to calculate the variance of a difference between two dependent proportions. For the difference in FECs, 95\% CIs were based on the standard formula for variance of a variable, in casu difference in FEC at the subject level. Finally, two random effect models were built for each metric with the difference in metric as outcome and pairwise comparisons as factor (three levels; $1 \times 1 \mathrm{KK}$ vs $2 \times 2 \mathrm{KK} ; 1 \times 2$ vs $2 \times 2 \mathrm{KK}$; and $2 \times 1 \mathrm{KK}$ vs $2 \times 2 \mathrm{KK}$ ), for S. mansoni and each of the three STH infections.

Second, we performed a meta-analysis to compare $\mathrm{CR}$ and ERR between $2 \times 2 \mathrm{KK}$ and $1 \times 1 \mathrm{KK}$, $1 \times 2$ KK, $2 \times 1$ KK among subjects who were excreting helminth eggs at baseline based on a single Kato-Katz thick smear. The difference in CR and ERR were calculated for each of the three pairwise comparisons $(1 \times 1 \mathrm{KK}$ vs $2 \times 2 \mathrm{KK} ; 1 \times 2 \mathrm{KK}$ vs $2 \times 2 \mathrm{KK}$; and $2 \times 1 \mathrm{KK}$ vs $2 \times 2 \mathrm{KK})$ across the six trials (trials I-VI), and four helminth species 
(S. mansoni, A. lumbricoides, hookworm and T. trichiura), resulting in 60 estimates $(2$ metrics $\times$ 3 comparisons $\times(4$ trials $\times 1$ helminth species + 2 trials $\times 3$ helminth species)). The ERR was calculated based on the formula below (Vercruysse et al. 2011).

$$
\mathrm{ERR}=\frac{\begin{array}{c}
\text { arithmetic mean } \\
\text { (baseline FEC) }
\end{array}-\begin{array}{c}
\text { arithmetic mean } \\
(\text { follow-up FEC) }
\end{array}}{\text { arithmetic mean }(\text { baseline FEC) }}
$$

A 95\% CI taking into account the correlation between results was calculated for each estimate based on bootstrap analysis (10000 iterations), because analogously to prevalence there is no standard formula to calculate the variance of a difference in two dependent $\mathrm{CR}$ and ERR results. Finally, one random effect model was built for each drug efficacy metric with the difference in the metric as outcome and the pairwise comparisons (three levels: $1 \times 1 \mathrm{KK}$ vs $2 \times 2 \mathrm{KK} ; 1 \times 2 \mathrm{KK}$ vs $2 \times 2 \mathrm{KK}$; and $2 \times 1 \mathrm{KK}$ vs $2 \times 2 \mathrm{KK})$ as factor. Due to the limited number of trials, the drug efficacy results of $S$. mansoni and STH infections were combined. The level of significance was set at $P<0 \cdot 05$. The meta-analysis was performed using the statistical software R 'metafor' package (Viechtbauer, 2010).

Assessment of helminth infection across three levels of endemicity. We performed a meta-analysis to compare prevalence and FEC results according to $1 \times 2 \mathrm{KK}$ with those after $1 \times 1 \mathrm{KK}$. To this end, differences in prevalence and FEC were calculated across the different schools and four helminth species (S. mansoni, A. lumbricoides, hookworm and T. trichiura). However, we only included schools for which the prevalence was at least $1 \%$, resulting in 84 estimates for S. mansoni, 128 for A. lumbricoides, 240 for hookworm and 220 for $T$. trichiura infections. A $95 \%$ CI taking into account the correlation between the results was calculated for each estimate as described above.

To assess the impact of diagnostic effort across varying levels of endemicity, we classified the schools into three levels of endemicity based on the helminth prevalence obtained by $2 \times 1 \mathrm{KK}$. For each of the four helminths, schools were classified into 'low endemic' when prevalence ranged from $\geqslant 1$ to $<10 \%$, into 'moderate endemic' when prevalence ranged from $\geqslant 10$ to $<20 \%$ and into 'high endemic' when the prevalence was $\geqslant 20 \%$. These thresholds defining endemicity are largely based on the prevalence values applied to determine the frequency of PC recommended by WHO, including 1, 10, 20 and 50\% (WHO, 2011). However, we did not use the 50\% threshold, as only a few schools had a prevalence that exceeded 50\%. Finally, two random effect models were built for prevalence and FEC with the difference in these metrics at the school level as outcome and the level of endemicity as factor (three levels: low, moderate and high), for S. mansoni and the three STH species separately. The level of significance was set at $P<0 \cdot 05$. The meta-analysis was performed using the statistical software R 'metafor' package (Viechtbauer, 2010).

\section{Ethical approval}

The four trials assessing the efficacy of $\mathrm{PZQ}$ against $S$. mansoni were approved by the London School of Hygiene and Tropical Medicine (London, UK; application no. LSHTM 5538.09) and the Ugandan National Council of Science and Technology. The trial assessing the efficacy of ALB and MEB alone or in combination with IVM against STH infections in Zanzibar was approved by the 'Ethikkommission beider Basel' (EKBB, Basel, Switzerland; reference no. 13/09) and the Zanzibar Medical Research Ethical Committee of the Ministry of Health (ZAMEC/0001/09). This trial is registered with Current Controlled Trials (ISRCTN08336605). The trial comparing the efficacy of single-dose and triple-dose ALB and MEB against STH infections in the People's Republic of China was approved by EKBB (reference no. 294/08) and the Academic Board of the National Institute of Parasitic Diseases, Chinese Center for Disease Control and Prevention in Shanghai (reference no. 2008091701). This trial is registered with Current Controlled Trials (ISRCTN47375023). The epidemiological survey conducted in Kenya received ethical approval from the ethics review committees of Kenya Medical Research Institute.

\section{RESULTS}

\section{Assessment of helminth infection and drug efficacy}

Helminth infection. Figures 3 and 4 summarize the results of the meta-analysis of differences in prevalence and FECs across the three pairwise comparisons for $S$. mansoni and STH infections, respectively. When referring to prevalence, there was a significant under-estimation (lower limit of 95\% $\mathrm{CI}>0$ ) of both $S$. mansoni and STH prevalence between $2 \times 2 \mathrm{KK}$ and $1 \times 1 \mathrm{KK}, 1 \times 2 \mathrm{KK}$ or $2 \times 1$ $\mathrm{KK}$, respectively. This difference in prevalence compared with $2 \times 2 \mathrm{KK}$ increased as a function of reduced sampling and diagnostic efforts for both $S$. mansoni and STH infections. For S. mansoni infections, the respective difference was $4 \cdot 0 \%(95 \%$ CI: $0.9 ; 7 \cdot 2 \%, P=0.014)$ for $2 \times 1 \mathrm{KK}, 10 \cdot 4 \%$ (95\% CI: $6 \cdot 8 ; 14 \cdot 0 \%, P<0.001)$ for $1 \times 2 \mathrm{KK}$ and $13 \cdot 7 \%(95 \% \mathrm{CI}: 9 \cdot 9 ; 17 \cdot 5 \%, P<0 \cdot 001)$ for $1 \times 1 \mathrm{KK}$. For STH infections, the difference was $3 \cdot 4 \%$ (95\% CI: $0 \cdot 5 ; 6 \cdot 3 \%, P=0 \cdot 002)$ ) $6 \cdot 0 \%$ (95\% CI: $3 \cdot 0$; $8 \cdot 9 \%, P<0 \cdot 001)$ and $10 \cdot 8 \%(95 \% \mathrm{CI}: 7 \cdot 7 ; 13 \cdot 8 \%$, 


\begin{tabular}{|c|c|c|c|c|c|c|}
\hline Effort & Trial & $\mathrm{n}$ & Time point & $\begin{array}{l}\text { Prevalence } \\
(\%)\end{array}$ & & $\begin{array}{l}\text { Difference in prevalence } \\
(\%)[95 \% \mathrm{Cl}]\end{array}$ \\
\hline \multirow[t]{8}{*}{$1 \times 1 \mathrm{KK}$} & 1 & 139 & Baseline & 69.8 & $\$-1$ & $12.9[7.9,18.7]$ \\
\hline & & & Follow-up & 33.8 & $10-1$ & $15.1[9.4,20.9]$ \\
\hline & $\|$ & 111 & Baseline & 17.1 & 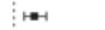 & $9.0[4.5,14.4]$ \\
\hline & & & Follow-up & 2.7 & $=-1$ & $2.7[0.0,6.3]$ \\
\hline & III & 61 & Baseline & 95.1 & $\mapsto$ & $18.0[9.8,27.9]$ \\
\hline & & & Follow-up & 45.9 & $\longmapsto$ & $27.9[16.4,39.3]$ \\
\hline & IV & 95 & Baseline & 68.4 & $1--1$ & $16.8[9.5,24.2]$ \\
\hline & & & Follow-up & 20.0 & $:-1$ & $7.4[3.2,12.6]$ \\
\hline \multirow[t]{8}{*}{$1 \times 2 \mathrm{KK}$} & 1 & 139 & Baseline & 69.8 & -1 & $8.6[4.3,13.7]$ \\
\hline & & & Follow-up & 33.8 & $\mapsto-1$ & $12.2[7.2,18.0]$ \\
\hline & ॥ & 111 & Baseline & 17.1 & $\vdots$ & $9.0[4.5,14.4]$ \\
\hline & & & Follow-up & 2.7 & $=1$ & $2.7[0.0,6.3]$ \\
\hline & III & 61 & Baseline & 95.1 & $\mapsto-1$ & $13.1[4.9,21.3]$ \\
\hline & & & Follow-up & 45.9 & $\mapsto$ & $23.0[13.1,34.4]$ \\
\hline & IV & 95 & Baseline & 68.4 & $\mapsto-1$ & $11.6[5.3,17.9]$ \\
\hline & & & Follow-up & 20.0 & in & $3.2[0.0,7.4]$ \\
\hline \multirow[t]{8}{*}{$2 \times 1 \mathrm{KK}$} & 1 & 139 & Baseline & 69.8 & $\vdots+1$ & $5.8[2.2,10.1]$ \\
\hline & & & Follow-up & 33.8 & - & $2.9[0.7,5.8]$ \\
\hline & ॥ & 111 & Baseline & 17.1 & 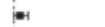 & $2.7[0.0,6.3]$ \\
\hline & & & Follow-up & 2.7 & 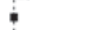 & $0.0[0.0,0.0]$ \\
\hline & III & 61 & Baseline & 95.1 & $-\infty$ & $4.9[0.0,11.5]$ \\
\hline & & & Follow-up & 45.9 & $i=-1$ & $6.6[1.6,13.1]$ \\
\hline & IV & 95 & Baseline & 68.4 & 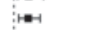 & $6.3[2.1,11.6]$ \\
\hline & & & Follow-up & 20.0 & $=1$ & $3.2[0.0,7.4]$ \\
\hline \multirow{5}{*}{$\begin{array}{l}1 \times 1 \mathrm{KK} \\
1 \times 2 \mathrm{KK} \\
2 \times 1 \mathrm{KK}\end{array}$} & & & & & $\bullet$ & $13.7[9.9,17.5]$ \\
\hline & & & & & $\bullet$ & $10.4[6.8,14.0]$ \\
\hline & & & & & $\bullet$ & $4.0[0.9,7.2]$ \\
\hline & & & & $T$ & $T$ & ᄀ \\
\hline & & & & $\begin{array}{ll}-50 & -25\end{array}$ & 25 & 50 \\
\hline
\end{tabular}

\begin{tabular}{|c|c|c|c|c|c|c|c|}
\hline Effort & Trial & $n$ & Time point & $\begin{array}{l}\text { Mean FEC } \\
\text { (EPG) }\end{array}$ & & & $\begin{array}{l}\text { Difference in FEC } \\
\text { (EPG) }[95 \% \mathrm{Cl}]\end{array}$ \\
\hline \multirow[t]{8}{*}{$1 \times 1 \mathrm{KK}$} & 1 & 139 & Baseline & 402 & $\longmapsto$ & $\longrightarrow$ & $22[-64,108]$ \\
\hline & & & Follow-up & 109 & $\longmapsto$ & & $-21[-62,20]$ \\
\hline & " & 111 & Baseline & 49 & $\longmapsto \vdots$ & & $0[-52,52]$ \\
\hline & & & Follow-up & 2 & 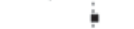 & & $2[0,4]$ \\
\hline & III & 61 & Baseline & 321 & & & $43[-20,106]$ \\
\hline & & & Follow-up & 34 & $\sum_{1}$ & & $13[2,24]$ \\
\hline & IV & 95 & Baseline & 207 & $\longrightarrow$ & & $-66[-125,-7]$ \\
\hline & & & Follow-up & 24 & $\stackrel{1}{\leftrightarrow}$ & & $11[-9,31]$ \\
\hline \multirow[t]{8}{*}{$1 \times 2 \mathrm{KK}$} & 1 & 139 & Baseline & 402 & : & & $15[-67,97]$ \\
\hline & & & Follow-up & 109 & $\mapsto-1$ & & $-11[-41,19]$ \\
\hline & $\|$ & 111 & Baseline & 49 & 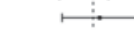 & & $8[-37,53]$ \\
\hline & & & Follow-up & 2 & 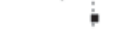 & & $2[0,4]$ \\
\hline & III & 61 & Baseline & 321 & ڤ- & & $37[-25,99]$ \\
\hline & & & Follow-up & 34 & $j=-1$ & & $15[3,27]$ \\
\hline & IV & 95 & Baseline & 207 & $\longrightarrow$ & & $-59[-114,-4]$ \\
\hline & & & Follow-up & 24 & $\leftrightarrow$ & & $10[-11,31]$ \\
\hline \multirow[t]{8}{*}{$2 \times 1 \mathrm{KK}$} & 1 & 139 & Baseline & 402 & 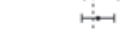 & & $6[-14,26]$ \\
\hline & & & Follow-up & 109 & iol & & $-5[-12,2]$ \\
\hline & ॥ & 111 & Baseline & 49 & of & & $-5[-12,2]$ \\
\hline & & & Follow-up & 2 & i & & $0[-1,1]$ \\
\hline & III & 61 & Baseline & 321 & $\mapsto$ & & $1[-24,26]$ \\
\hline & & & Follow-up & 34 & 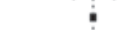 & & $0[-3,3]$ \\
\hline & IV & 95 & Baseline & 207 & +1 & & $-2[-13,9]$ \\
\hline & & & Follow-up & 24 & 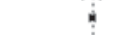 & & $-1[-4,2]$ \\
\hline $1 \times 1 \mathrm{KK}$ & & & & & - & & $0[-17,18]$ \\
\hline $1 \times 2 \mathrm{KK}$ & & & & & - & & $2[-14,18]$ \\
\hline \multirow[t]{3}{*}{$2 \times 1 \mathrm{KK}$} & & & & & $!$ & & $-1[-5,4]$ \\
\hline & & & & $\Gamma$ & $T$ & $T$ & ᄀ \\
\hline & & & & -150 & .75 & 75 & 150 \\
\hline
\end{tabular}

Fig. 3. The effect of sampling and diagnostic efforts on the assessment of Schistosoma mansoni infection. Forest plots comparing the prevalence and faecal egg count (FEC) results for $S$. mansoni between a single Kato-Katz thick smear from one stool sample $(1 \times 1 \mathrm{KK})$, duplicate Kato-Katz thick smears from one sample $(1 \times 2 \mathrm{KK})$ and a single Kato-Katz thick smear from two consecutive stool samples $(2 \times 1 \mathrm{KK})$ with those based on duplicate Kato-Katz thick smears from two consecutive stool samples $(2 \times 2 \mathrm{KK})$ on all subjects both at baseline and treatment follow-up $(n=406)$.

$P<0 \cdot 001)$ for $2 \times 1 \mathrm{KK}, 1 \times 2 \mathrm{KK}$ and $1 \times 1 \mathrm{KK}$, respectively.

When summarizing infection intensity as FEC, there was no significant difference in FEC for $1 \times 1$ $\mathrm{KK}, 1 \times 2 \mathrm{KK}$ and $2 \times 1 \mathrm{KK}$ compared with $2 \times 2 \mathrm{KK}$ for both $S$. mansoni and STH infections. For $S$. mansoni infection, the difference was 0 eggs per $1 \mathrm{~g}$ of stool (EPG) $(95 \% \mathrm{CI}:-17 ; 18 \mathrm{EPG}, P=0 \cdot 96)$ for $1 \times 1 \mathrm{KK}, 2 \mathrm{EPG}(95 \% \mathrm{CI}:-14 ; 18 \mathrm{EPG}$, $P=0 \cdot 80)$ for $1 \times 2 \mathrm{KK}$ and $-1 \mathrm{EPG}(95 \% \mathrm{CI}:-5$; $4 \mathrm{EPG}, P=0 \cdot 74$ ) for $2 \times 1 \mathrm{KK}$. For STH infections, the difference was -130 EPG $(95 \%$ CI: -291 ; $30 \mathrm{EPG}, P=0 \cdot 11)$ for $1 \times 1 \mathrm{KK},-119 \mathrm{EPG}(95 \% \mathrm{CI}$ : $-274 ; 36 \mathrm{EPG}, P=0 \cdot 13)$ for $1 \times 2 \mathrm{KK}$ and $-4 \mathrm{EPG}$ (95\% CI: -156 ; $148 \mathrm{EPG}, P=0 \cdot 95)$ for $2 \times 1 \mathrm{KK}$.

Drug efficacy. Figure 5 summarizes the differences in $\mathrm{CR}$ and ERR for the three pairwise comparisons for $S$. mansoni and STH infections combined. When referring to drug efficacy by $\mathrm{CR}$, there was an overall over-estimation (difference $<0$ ) of CR between $2 \times 2$ $\mathrm{KK}$ and $1 \times 1 \mathrm{KK}, 1 \times 2 \mathrm{KK}$, or $2 \times 1 \mathrm{KK}$. However, the difference in $\mathrm{CR}$ compared with $2 \times 2 \mathrm{KK}$ decreased in function of reduced sampling and diagnostic effort, ranging from a marginal non-significant difference of $-3 \cdot 6 \%(95 \% \mathrm{CI}:-7 \cdot 6 ; 0 \cdot 3 \%, P=0 \cdot 069)$ for $2 \times 1 \mathrm{KK}$, over an already significant difference of $-9 \cdot 8 \%(95 \% \mathrm{CI}:-14 \cdot 3 ;-5 \cdot 3 \%, P<0 \cdot 001)$ for $1 \times 2$ KK to a highly significant difference of $-14 \cdot 6 \%(95 \%$ CI: $-19 \cdot 3 ;-9.9 \%, P<0 \cdot 001)$ for $1 \times 1 \mathrm{KK}$. When summarizing changes in infection as ERR, there was no significant difference in ERR compared to $2 \times 2$ $\mathrm{KK}$ for $1 \times 1 \mathrm{KK}(-2 \cdot 5 \quad$ [95\% CI: $-7 \cdot 1 ; 2 \cdot 2]$, $P=0 \cdot 31), 1 \times 2$ KK $(-2 \cdot 4 \quad[95 \%$ CI: $-5 \cdot 9 ; 1 \cdot 0]$, $P=0 \cdot 17)$, and $2 \times 1 \mathrm{KK}(-1 \cdot 3$ [95\% CI: $-2 \cdot 7 ; 0 \cdot 1]$, $P=0 \cdot 077)$.

Assessment of helminth infection across three levels of endemicity

Figures 6 to 9 summarize the results of the metaanalysis of differences in prevalence and FECs across the three levels of endemicity for $S$. mansoni, $A$. lumbricoides, hookworm and $T$. trichiura infections, respectively. When referring to prevalence, there was significant under-estimation for S. mansoni infections in low $(+1 \cdot 4 \%$ [95\% CI: $+0 \cdot 5 ;+2 \cdot 3 \%]$, $P=0.001)$ and high endemic schools $(+2.9 \%[95 \%$ CI: $+2 \cdot 1 ;+3 \cdot 7 \%$ ], $P<0 \cdot 001)$, but not in the moderate endemic schools $(+1 \cdot 3 \%$ [95\% CI: $-0 \cdot 2 ;+2 \cdot 9 \%]$, $P=0.096)$. For the STH species there was a significant under-estimation (lower limit of $95 \% \mathrm{CI}>0$ ) at the three levels of endemicity for each of the three STH species. For these helminth species the difference in prevalence compared with $1 \times 2 \mathrm{KK}$ also increased as a function of increasing levels of endemicity. For $A$. lumbricoides infections, the difference was $+0 \cdot 7 \%(95 \% \mathrm{CI}:+0 \cdot 5 ;+0 \cdot 9 \%, P<0 \cdot 001)$ for low endemic schools, $+1 \cdot 5 \%$ (95\% CI: $+0 \cdot 9$; $+2 \cdot 0 \%$, $P<0.001)$ for moderate endemic schools and $+2 \cdot 0 \%$ (95\% CI: $+0 \cdot 9$; $+3 \cdot 2 \%, P<0 \cdot 001)$ for high endemic schools. For hookworm and $T$. trichiura, this 


\begin{tabular}{|c|c|c|c|c|c|c|c|}
\hline Effort & STH & Trial & $\mathrm{n}$ & Time point & $\begin{array}{l}\text { Prevalence } \\
(\%)\end{array}$ & & $\begin{array}{l}\text { Difference in prevalence } \\
\begin{array}{ll}\text { (\%) }[95 \% \mathrm{Cl}]\end{array}\end{array}$ \\
\hline \multirow[t]{11}{*}{$1 \times 1 \mathrm{kK}$} & A. lumbricoides & v & 535 & Baseline & 12.0 & $\vdots=1$ & $2.6[1.3,4.1]$ \\
\hline & & & & Follow-up & 1.7 & & $0.6[0.0,1.3]$ \\
\hline & & VI & 314 & Baseline & 90.4 & $\vdots+\infty$ & $2.9[1.3,4.8]$ \\
\hline & Hookworm & $v$ & 535 & Follow-up & 4.8 & $t^{t=1}$ & $\begin{array}{r}1.6[0.3,3.2] \\
108[82.136,\end{array}$ \\
\hline & & & & Follow-up & 18.9 & $\mapsto$ & $9.0[6.7,11.4]$ \\
\hline & & vi & 314 & Baseline & 72.6 & $\longmapsto$ & $19.7[15.3,24.2]$ \\
\hline & & & & Follow-up & 29.3 & $\mapsto$ & $11.8[8.3,15.3]$ \\
\hline & $T$. trichiura & $v$ & 535 & Baseline & 100 & & $15.5[12.5,18.7]$ \\
\hline & & & & Follow-up & 69.5 & & $17.6[14.4,20.9]$ \\
\hline & & vi & 314 & Baseline & 74.5 & $\longmapsto$ & $21.7[17.2,26.4]$ \\
\hline & & & & Follow-up & 40.4 & $\mapsto$ & $15.3[11.5,19.4]$ \\
\hline \multirow[t]{12}{*}{$1 \times 2 \mathrm{KK}$} & A. lumbricoides & $v$ & 535 & Baseline & 12.0 & 我 & $2.2[1.1,3.6]$ \\
\hline & & & & Follow-up & 1.7 & & $0.2[0.0,0.6]$ \\
\hline & & vi & 314 & Baseline & 90.4 & :-1 & $2.5[1.0,4.5]$ \\
\hline & & & & Follow-up & 4.8 & $i=1$ & $1.0[0.0,2.2]$ \\
\hline & Hookworm & v & 535 & Baseline & 25.8 & $\vdots=-1$ & $6.0[4.1,8.0]$ \\
\hline & & & & Follow-up & 18.9 & Her & $4.7[3.0,6.5]$ \\
\hline & & vi & 314 & Baseline & 72.6 & $\longmapsto-1$ & $14.6[10.8,18.5]$ \\
\hline & & & & Follow-up & 29.3 & $\vdots \mapsto-1$ & $7.6[4.8,10.5\}$ \\
\hline & T. trichiura & v & 535 & Baseline & 100 & & $0.0[0.0,0.0]$ \\
\hline & & & & Follow-up & 69.5 & $\mapsto-1$ & $9.5[7.1,12.1]$ \\
\hline & & vi & 314 & Baseline & 74.5 & $\mapsto$ & $13.4[9.9,17.2]$ \\
\hline & & & & Follow-up & 40.4 & $\mapsto \curvearrowleft$ & $9.9[6.7,13.4]$ \\
\hline \multirow[t]{11}{*}{$2 \times 1 \mathrm{kK}$} & A. lumbricoides & v & 535 & Baseline & 12.0 & $m$ & $1.1[0.4,2.1]$ \\
\hline & & & & Follow-up & 1.7 & 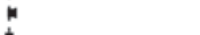 & $0.4[0.0,0.9]$ \\
\hline & & vi & 314 & Baseline & 90.4 & 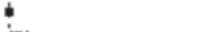 & $0.0[0.0,0.0]$ \\
\hline & Hookworm & $v$ & 535 & $\begin{array}{l}\text { Follow-up } \\
\text { Baseline }\end{array}$ & $\begin{array}{l}4.8 \\
25.8\end{array}$ & 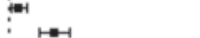 & $\begin{array}{l}1.3[0.3,2.5] \\
64[4,86]\end{array}$ \\
\hline & & & & Follow-up & 18.9 & & $3.2[1.9,4.7]$ \\
\hline & & vi & 314 & Baseline & 72.6 & $\mapsto-1$ & $4.1[1.9,6.4]$ \\
\hline & & & & Follow-up & 29.3 & $H$ & $3.5[1.6,5.7]$ \\
\hline & T. trichiura & $\mathrm{v}$ & 535 & Baseline & 100 & 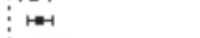 & $4.3[2.6,6.2]$ \\
\hline & & & & Follow-up & 69.5 & $\mapsto$ & $6.2[4.1,8.4]$ \\
\hline & & vi & 314 & Baseline & 74.5 & $\mapsto-1$ & $5.7[3.2,8.6]$ \\
\hline & & & & Follow-up & 40.4 & $H-1$ & $4.8[2.5,7.3]$ \\
\hline \multirow{4}{*}{$\begin{array}{l}1 \times 1 \mathrm{KK} \\
1 \times 2 \mathrm{KK} \\
2 \times 1 \mathrm{KK}\end{array}$} & & & & & & & $10.8[7.7,13.8]$ \\
\hline & & & & & & & $6.0[3.0,8.9]$ \\
\hline & & & & & & & $3.4[0.5,6.3]$ \\
\hline & & & & & & & \\
\hline
\end{tabular}

Difference in prevalence (\%)

\begin{tabular}{|c|c|c|c|c|c|c|c|}
\hline Effort & STH & Trial & $\mathrm{n}$ & Time point & $\begin{array}{l}\text { Mean FEC } \\
\text { (EPG) }\end{array}$ & & $\begin{array}{l}\text { Difference in FEC } \\
\text { (EPG) }[95 \% \mathrm{Cl}]\end{array}$ \\
\hline \multirow[t]{10}{*}{$1 \times 1 \mathrm{KK}$} & A. lumbricoides & $\mathrm{v}$ & 535 & $\begin{array}{l}\text { Baseline } \\
\text { Follow-up }\end{array}$ & $\begin{array}{l}1303 \\
191\end{array}$ & $\stackrel{1}{\longmapsto}$ & $\begin{array}{r}-40[-360,279] \\
-190[-488,107]\end{array}$ \\
\hline & & VI & 314 & Baseline & 20377 & $\vdots$ & $-1357[-1676,-1038]$ \\
\hline & & & & Follow-up & & & $19[-279,316]$ \\
\hline & Hookworm & $\mathrm{v}$ & 535 & Baseline & 53 & i & $5[-12,21\}$ \\
\hline & & & & Follow-up & & 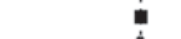 & $4[-3,10 j$ \\
\hline & & VI & 314 & Baseline & 110 & 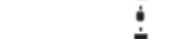 & $-6[-22, \quad 11 j$ \\
\hline & $T$ trichiure & v & 535 & Follow-up & $\begin{array}{l}21 \\
369\end{array}$ & $\dot{\phi}$ & $\begin{aligned} 21 & -5,9]\end{aligned}$ \\
\hline & 1. mentura & $v$ & 535 & $\begin{array}{l}\text { Baseline } \\
\text { Eollow-4n }\end{array}$ & $\begin{array}{l}369 \\
263\end{array}$ & 索 & $11\left[\begin{array}{cc}-55, & 77]\end{array}\right]$ \\
\hline & & vi & 314 & Baseline & 81 & in & 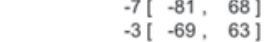 \\
\hline & & & & Follow-up & 40 & $i=1$ & $1[-74,75]$ \\
\hline \multirow[t]{12}{*}{$1 \times 2 \mathrm{KK}$} & A. lumbricoides & $\mathrm{v}$ & 535 & Baseline & 1303 & $\mapsto$ & $12[-224,247]$ \\
\hline & & & & Follow-up & 191 & $\rightarrow$ & $-95[-234,43]$ \\
\hline & & vi & 314 & Baseline & 20377 & $\mapsto$ & $-1414[-1649,-1178]$ \\
\hline & & & & Follow-up & & & $20[-118,159]$ \\
\hline & Hookworm & $\mathrm{v}$ & 535 & Baseline & 53 & ; & $4[-10,17]$ \\
\hline & & & & Follow-up & & - & $7[0,14]$ \\
\hline & & vi & 314 & Baseline & 110 & b & $-2[-15,12]$ \\
\hline & & & & Follow-up & 21 & $\dot{\varphi}$ & $3[-4,10]$ \\
\hline & T. trichiura & $\mathrm{v}$ & 535 & Baseline & 369 & $\bar{\mu}$ & $32[-8,71]$ \\
\hline & & & & Follow-up & 263 & * & $9[-35,54]$ \\
\hline & & VI & 314 & Baseline & 81 & in & $1[-38,40]$ \\
\hline & & & & Follow-up & 40 & $\dot{\varphi}$ & $-1[-45,44]$ \\
\hline \multirow[t]{11}{*}{$2 \times 1 \mathrm{KK}$} & A. lumbricoides & $\mathrm{v}$ & 535 & Baseline & 1303 & بَّتَ & $-53[-191,85]$ \\
\hline & & & & Follow-up & 191 & $i$ & $0[-29,30]$ \\
\hline & & VI & 314 & Baseline & 20377 & +1 & $13[-125,151]$ \\
\hline & & & & Follow-up & 71 & $\dot{\varphi}$ & $-1[-31,28]$ \\
\hline & Hookworm & v & 535 & Baseline & 53 & 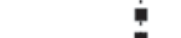 & $4[-3,12]$ \\
\hline & & & & Follow-up & 35 & 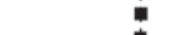 & $4[-3,10]$ \\
\hline & & VI & 314 & Baseline & 110 & 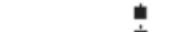 & $-4[-11,3]$ \\
\hline & & & & Follow-up & 21 & ب & $0\left[\begin{array}{r}-7,6 \\
0\end{array}\right]$ \\
\hline & T. trichiura & $\mathrm{v}$ & 535 & $\begin{array}{l}\text { Baseline } \\
\text { Follow-up }\end{array}$ & $\begin{array}{l}369 \\
263\end{array}$ & 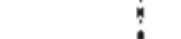 & 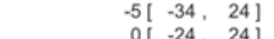 \\
\hline & & vi & 314 & Baseline & 81 & & $\begin{array}{c}0[-24, \\
-6[-35,23]\end{array}$ \\
\hline & & & & Follow-up & 40 & 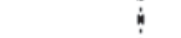 & $1[-23,25]$ \\
\hline \multirow{5}{*}{$\begin{array}{l}1 \times 1 \mathrm{KK} \\
1 \times 2 \times K \\
2 \times 1 \mathrm{KK}\end{array}$} & & & & & & - & $-130[-291,30]$ \\
\hline & & & & & & - & $-119[-274,36]$ \\
\hline & & & & & & 4 & $-4[-156,148]$ \\
\hline & & & & & 1 & 1 & $T$ \\
\hline & & & & & -2000 & -1000 & 2000 \\
\hline
\end{tabular}

Difference in $F E C$ (EPG)

Fig. 4. The effect of sampling and diagnostic efforts on the assessment of soil-transmitted helminth infection. Forest plots comparing the prevalence and faecal egg count (FEC) results for soil-transmitted helminth infections (Ascaris lumbricoides, hookworm and Trichuris trichiura) between a single Kato-Katz thick smear from one stool sample $(1 \times 1 \mathrm{KK})$, duplicate Kato-Katz thick smears from one sample $(1 \times 2 \mathrm{KK})$, and a single Kato-Katz thick smear from two consecutive stool samples $(2 \times 1 \mathrm{KK})$ with those based on duplicate Kato-Katz thick smears from two consecutive stool samples $(2 \times 2 \mathrm{KK})$ on all subjects both at baseline and treatment follow-up $(n=849)$. 

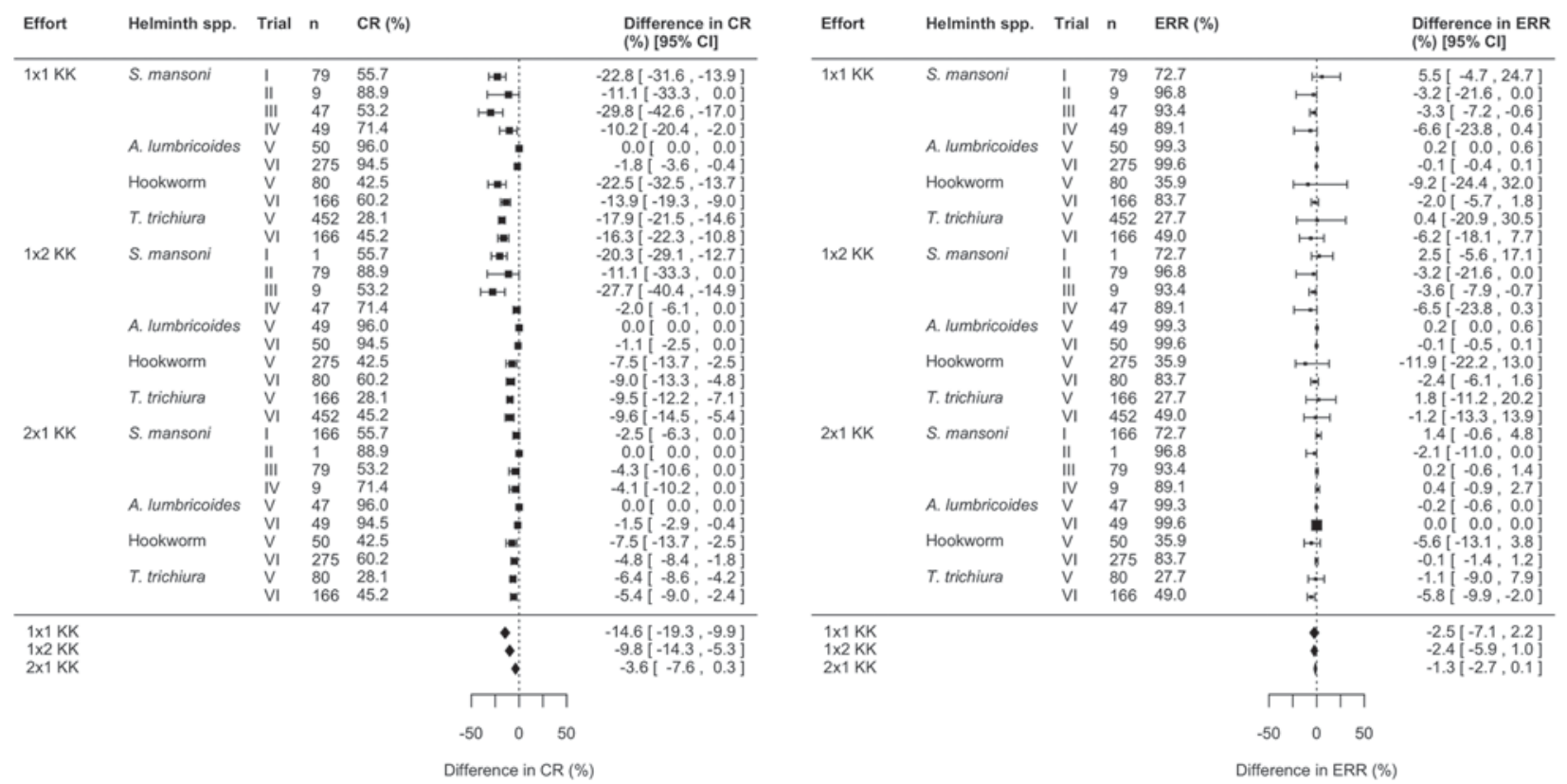

Fig. 5. The effect of sampling and diagnostic efforts on the reported drug efficacy against helminth infections. Forest plot comparing the cure rate (CR) and egg reduction rate (ERR) results against Schistosoma mansoni and soil-transmitted helminth infections (Ascaris lumbricoides, hookworm and Trichuris trichiura) between a single Kato-Katz thick smear on one stool sample $(1 \times 1 \mathrm{KK})$, duplicate Kato-Katz thick smears on one sample $(1 \times 2 \mathrm{KK})$, and a single Kato-Katz thick smear on two consecutive stool samples $(2 \times 1 \mathrm{KK})$ with those based on duplicate Kato-Katz thick smears on two consecutive stool samples $(2 \times 2 \mathrm{KK})$ on all subjects found to excrete eggs using a single Kato-Katz thick smear $(n=939)$.

difference was $+1 \cdot 3 \% \quad(95 \%$ CI: $+0 \cdot 9 ; \quad+1 \cdot 7 \%$, T. trichiura, $P<0 \cdot 001)$ and $+1 \cdot 6 \%(95 \% \mathrm{CI}:+1 \cdot 1$; $+2 \cdot 1 \%$, hookworm, $P<0.001)$ for low endemic schools, $+4 \cdot 0 \%(95 \% \mathrm{CI}:+3 \cdot 1 ;+4 \cdot 8 \%$, hookworm, $P<0 \cdot 001)$ and $+4 \cdot 1 \% \quad(95 \%$ CI: $+3 \cdot 0 ; \quad+5 \cdot 2 \%$, T. trichiura, $P<0.001)$ for moderate endemic schools, and $+7 \cdot 8 \%(95 \% \mathrm{CI}:+6 \cdot 8$; $+8 \cdot 8 \%, \quad$ T. trichiura, $P<0 \cdot 001)$ and $+7.9 \%(95 \% \mathrm{CI}:+7 \cdot 0$; $+8 \cdot 9 \%$, hookworm, $P<0 \cdot 001)$ for high endemic schools.

When summarizing infection intensity as mean FEC at the school level, there was no significant difference in FEC for $1 \times 1 \mathrm{KK}$ compared with $1 \times 2 \mathrm{KK}$ at the three levels of endemicity for each of the four helminth species (95\% CI includes zero). There was no increase in difference as a function of increasing level of endemicity. For S. mansoni the difference varied from -1 EPG $(95 \% \mathrm{CI}$ : -2 ; +1 EPG,$P=0 \cdot 30)$ for moderate endemic schools to 15 EPG (95\% CI: -9 ; +38 EPG, $P=0 \cdot 22)$ for high endemic schools. For $A$. lumbricoides infection the difference in FEC ranged from $-8 \mathrm{EPG}(95 \% \mathrm{CI}$ : $-23 ;+7$ EPG, $P=0 \cdot 30)$ for moderate endemic schools to $141 \mathrm{EPG}(95 \% \mathrm{CI}:-66 ;+348 \mathrm{EPG}$, $P=0 \cdot 18$ ) for high endemic schools. For hookworm the difference in FEC varied from $-7 \mathrm{EPG}(95 \% \mathrm{CI}$ : -18 ; +3 EPG, $P=0 \cdot 18$ ) for high endemic schools to $1 \mathrm{EPG}(95 \% \mathrm{CI}:-1$; $+3 \mathrm{EPG}, P=0 \cdot 54)$ for low endemic schools. For $T$. trichiura this difference ranged from 0 EPG $(95 \% \mathrm{CI}:-3 ;+2 \mathrm{EPG}, P=0 \cdot 55)$ for moderate endemic schools to $3 \mathrm{EPG}(95 \% \mathrm{CI}:-1$; $+8 \mathrm{EPG}, P=0 \cdot 14$ ) for high endemic schools.
DISCUSSION

In the present study we determined the effect of sampling and diagnostic efforts on qualitative (prevalence and CR) and quantitative (FEC and ERR) metrics applied to characterize outcomes of anthelmintic drug administration targeting $S$. mansoni and STH infections. Our results support a prior hypothesis that maximizing stool sampling and diagnostic effort increases the accuracy of qualitative metrics (Knopp et al. 2011; Utzinger et al. 2011), but does not influence the accuracy of quantitative metrics.

Our findings therefore indicate that summarizing helminth infection intensity and drug efficacy by means of FEC and ERR based on a single Kato-Katz thick smear before and after treatment, rather than by prevalence and $\mathrm{CR}$, is as reliable as a more rigorous diagnostic approach. This observation has important ramifications and could translate into substantial cost savings. For example, Speich and colleagues estimated the total cost to perform single or duplicate Kato-Katz thick smears in the frame of an epidemiological study to be US $\$ 1.73$ and $2 \cdot 06$, respectively (Speich et al. 2010). By extrapolation one can deduce that maximizing sampling and diagnostic efforts (in casu quadruplicate Kato-Katz thick smears based on two stool samples) would cost US\$ $4 \cdot 12$ $(2 \times \mathrm{US} \$ 2 \cdot 06)$. To assess helminth infection in 100 subjects in one school by an experienced team, one would thus need to allocate US\$ 173 when summarizing infection intensity by means of FEC 

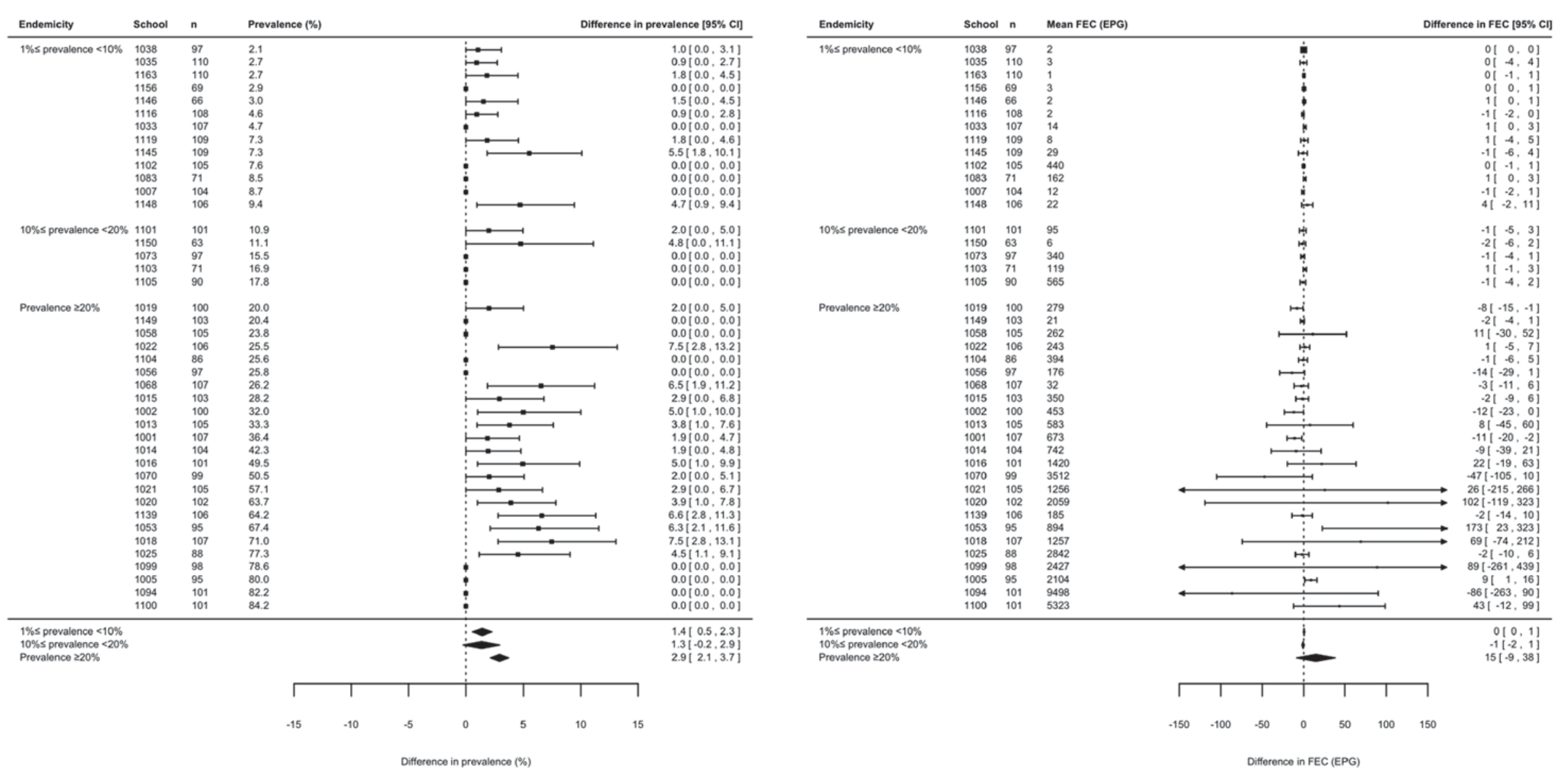

Fig. 6. The effect of diagnostic efforts on the assessment of three levels of Schistosoma mansoni infection. Forest plots comparing the prevalence and faecal egg count (FEC) results for $S$. mansoni between a single Kato-Katz thick smear from one stool sample $(1 \times 1 \mathrm{KK})$ with those obtained by duplicate Kato-Katz thick smears from one sample $(1 \times 2 \mathrm{KK})$ across three levels of endemicity (low: $1 \% \leqslant$ prevalence $<10 \%$, moderate: $10 \% \leqslant$ prevalence $<20 \%$, high: prevalence $\geqslant 20 \%)(n=4114)$. 

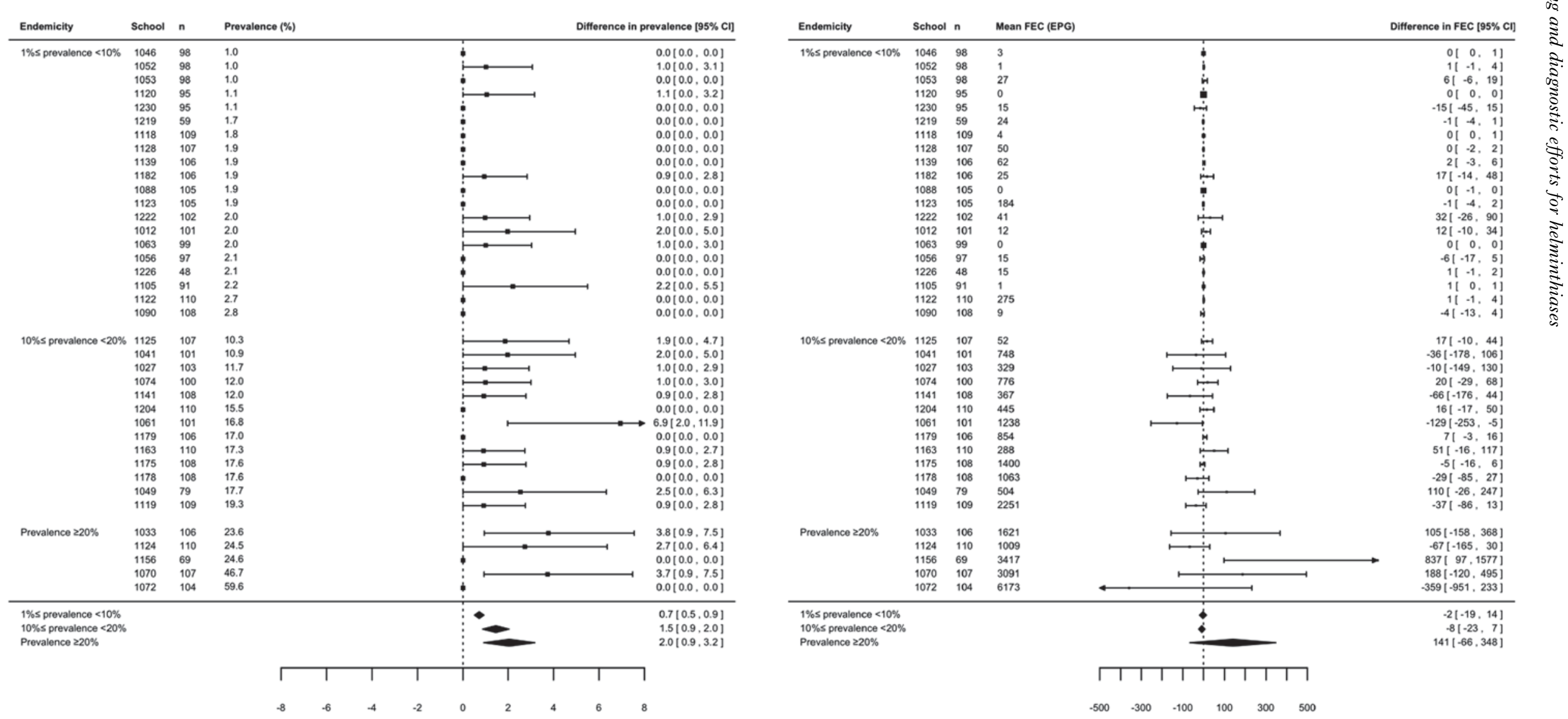

Fig. 7. The effect of diagnostic efforts on the assessment of three levels of Ascaris lumbricoides infection. Forest plots comparing the prevalence and faecal egg count (FEC) results for $A$. lumbricoides between a single Kato-Katz thick smear from one stool sample $(1 \times 1 \mathrm{KK})$ with those obtained by duplicate Kato-Katz thick smears from one sample $(1 \times 2 \mathrm{KK})$ across three levels of endemicity (low: $1 \% \leqslant$ prevalence $<10 \%$, moderate: $10 \% \leqslant$ prevalence $<20 \%$, high: prevalence $\geqslant 20 \%$ ). Due to the high number of schools for which prevalence $\geqslant 1 \%(n=64)$, we only present 20 out of 46 schools classified as low endemic, all 13 schools classified as moderate and all five schools classified as high endemic. The estimated difference in prevalence and infection intensity for each level of endemicity, however are based on all 64 schools $(n=6372)$. 


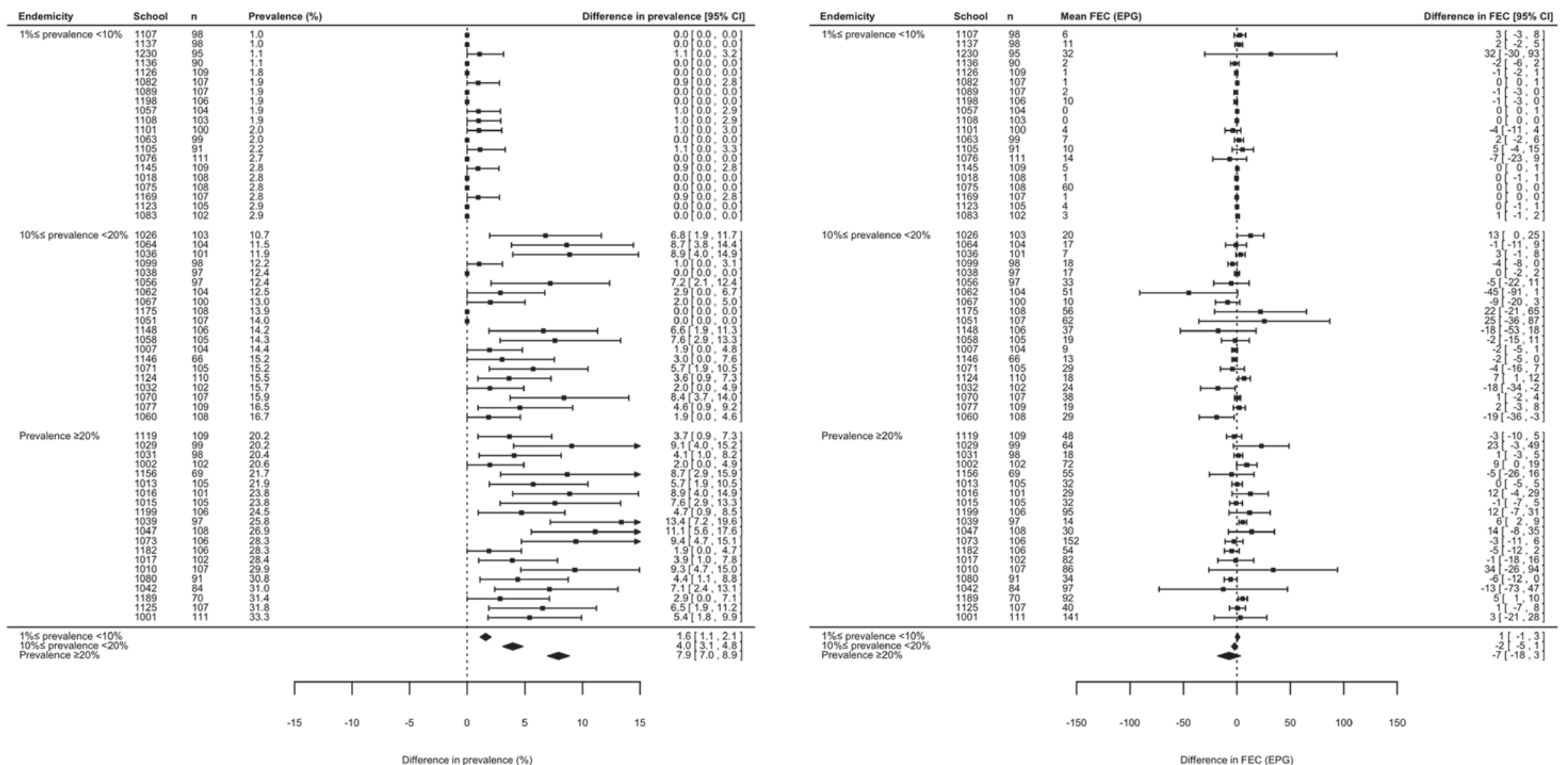

Fig. 8. The effect of diagnostic efforts on the assessment of three levels of hookworm infection. Forest plots comparing the prevalence and faecal egg count (FEC) results for hookworm between a single Kato-Katz thick smear from one stool sample $(1 \times 1 \mathrm{KK})$ with those obtained by duplicate Kato-Katz thick smears from one sample $(1 \times 2 \mathrm{KK})$ across three levels of endemicity (low: $1 \% \leqslant$ prevalence $<10 \%$, moderate: $10 \% \leqslant$ prevalence $<20 \%$, high: prevalence $\geqslant 20 \%$ ). Due to the high number of schools for which prevalence $\geqslant 1 \%(n=120)$, we only present 20 out of 56 schools classified as low endemic, 20 out of 27 schools classified as moderate and 20 out of 37 schools classified as high endemic. The estimated difference in prevalence and infection intensity for each level of endemicity, however are based on all 120 schools $(n=12217)$. 


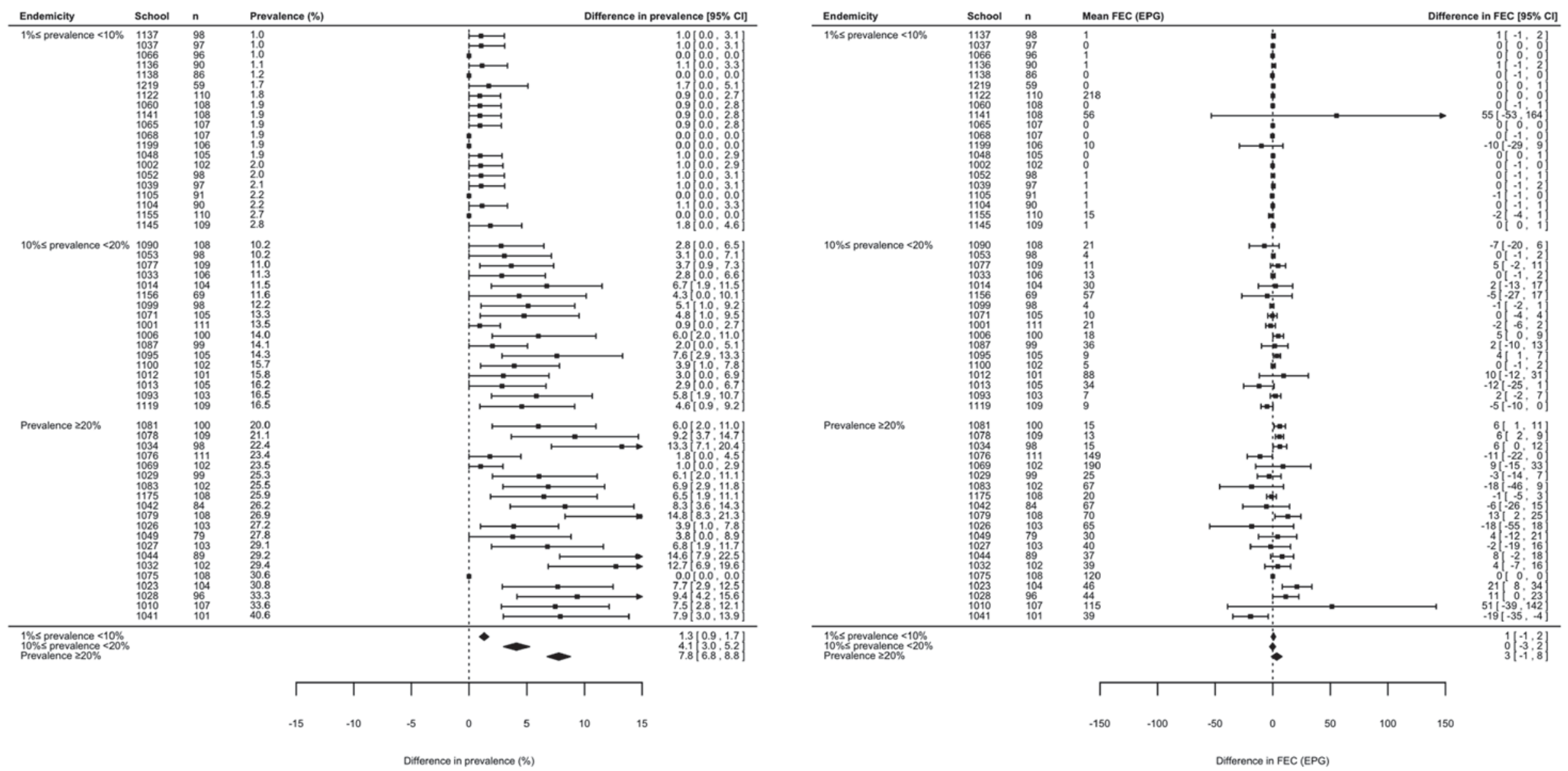

Fig. 9. The effect of diagnostic efforts on the assessment of three levels of Trichuris trichiura infection. Forest plots comparing the prevalence and faecal egg count (FEC) results for $T$. trichiura between a single Kato-Katz thick smear from one stool sample $(1 \times 1 \mathrm{KK})$ with those obtained by duplicate Kato-Katz thick smears from one sample $(1 \times 2 \mathrm{KK})$ across three levels of endemicity (low: $1 \% \leqslant$ prevalence $<10 \%$, moderate: $10 \% \leqslant$ prevalence $<20 \%$, high: prevalence $\geqslant 20 \%$ ). Due to the high number of schools for which prevalence $\geqslant 1 \%(\mathrm{n}=110)$, we only present 20 out of 62 schools classified as low endemic, all 17 schools classified as moderate and 20 out of 31 schools classified as high endemic. The estimated difference in prevalence and infection intensity for each level of endemicity, however are based on all 110 schools $(n=11067)$. 
(single Kato-Katz thick smear), whereas US\$ 412 would be needed for a more rigorous sampling and diagnostic work-up with quadruplicate Kato-Katz thick smears to more accurately determine the local prevalence. In other words, the same funds would support the screening of $2 \cdot 38 \quad(=412 / 173)$ times more subjects when summarizing infection intensity by $\mathrm{FEC}$ rather than CR. Also, note that these estimates do not include the additional time required for data entry, and hence are likely to be underestimated. Screening a larger number of subjects without compromising diagnostic accuracy would allow the inclusion of more schools across different geographical locations, and hence improve the precision of helminth disease mapping and prediction. This is particularly important given the large endemic areas and the focal distribution of these diseases (Brooker et al. 2010; Hürlimann et al. 2011; Pullan and Brooker, 2012). Our data also indicate that minimizing sampling and diagnostic effort is justified even in low-endemicity settings. Together with the fact that qualitative metrics impede interpretation of the long-term impact of PC and drug efficacy (Vercruysse et al. 2011; Anderson et al. 2012), we would like to encourage reporting of FEC and $\mathrm{ERR}$ in investigations describing the long-term impact of PC campaigns. Current WHO guidelines on the control of schistosomiasis and soiltransmitted helminthiasis are primarily based on prevalence, and hence FEC thresholds corresponding to the set prevalence thresholds will need to be developed if reporting should shift from infections towards FEC (WHO, 2011). Moreover, such FEC thresholds corresponding to prevalence will need to be developed for each of the three STH species separately (current thresholds are based on the prevalence of any STH) as fecundity of adult worms varies considerably from one species to another (A. lumbricoides $>>$ hookworm $>T$. trichiura; Bethony et al. 2006). Hence, a fixed FEC threshold for all STH is inappropriate. For drug efficacy monitoring, CR remains the most reported metric (Keiser and Utzinger, 2008; Danso-Appiah et al. 2013), but the WHO recently published new guidelines on how to assess and interpret anthelmintic drug efficacy based on ERR (WHO, 2013).

\section{CONCLUSIONS}

This study indicates that sampling and diagnostic efforts can be minimized to a single Kato-Katz thick smear if, and only if, helminth infection and drug efficacy are reported by means of both FEC and ERR. This however, implies a need for speciesspecific thresholds based on FEC corresponding to prevalence to determine the frequency of drug administration as outlined in WHO guidelines to control schistosomiasis and soil-transmitted helminthiasis.

\section{ACKNOWLEDGEMENTS}

We would like to thank the Neglected Tropical Diseases Control team of the Helminth Control Laboratory Unguja for their excellent and dedicated work in the field and laboratory in Zanzibar. We would also like to thank the team from the Vector Control Disease, Ministry of Health of Uganda, as well as Dr Martha Betson for their invaluable efforts during the field surveys in Uganda.

\section{FINANCIAL SUPPORT}

B.L. is a postdoctoral fellow of the Fund for Scientific Research-Flanders (Belgium) (F.W.O.-Vlaanderen, grant no. FWO12/PDO/099). S.J.B. is supported by a Wellcome Trust Senior Fellowship in Basic Biomedical Science (098045). S.K. acknowledges financial support from the Schistosomiasis Consortium for Operational Research and Evaluation (SCORE; sub-award no. RR374-053/4893196). S.K. and J.U. are grateful for partial financial support by the NIDIAG network (collaborative project; www. NIDIAG.org) supported by the European Commission under the Health Cooperation Work Programme of the 7 th Framework Programme (grant agreement no. 260260). J.R.S. and S.C.S.-F. acknowledge financial support from the Wellcome Trust (grant no. 085440 entitled 'SIMI: schistosomiasis in mothers and infants').

\section{REFERENCES}

Albonico, M., Ame, S. M., Vercruysse, J. and Levecke, B. (2012). Comparison of Kato-Katz thick smear and McMaster egg counting method for monitoring drug efficacy against soil-transmitted helminths in school children of Pemba Island, Tanzania. Transactions of the Royal Society of Tropical Medicine and Hygiene 107, 199-201.

Albonico, M., Rinaldi, L., Sciascia, S., Morgoglione, M. E., Piemonte, M., Maurelli, M. P., Musella, V., Utzinger, J., Ali, S. M. and Cringoli, G. (2013). Comparison of three copromicroscopic methods to assess albendazole efficacy against soil-transmitted helminth infections in school-aged children on Pemba Island. Transactions of the Royal Society of Tropical Medicine and Hygiene 107, 493-501.

Anderson, R., Hollingsworth, T.D., Truscott, J. and Brooker, S. (2012). Optimisation of mass chemotherapy to control soil-transmitted helminth infection. Lancet 379, 289-290.

Bergquist, R., Johansen, M. V. and Utzinger, J. (2009). Diagnostic dilemmas in helminthology: what tools to use and when? Trends in Parasitology 25, 151-156.

Bethony, J., Brooker, S., Albonico, M., Geiger, S. M., Loukas, A. Diemert, D. and Hotez, P. J. (2006). Soil-transmitted helminth infections: ascariasis, trichuriasis, and hookworm. Lancet 367, 1521-1532.

Booth, M., Vounatsou, P., N'Goran, E. K., Tanner, M. and Utzinger, J. (2003). The influence of sampling effort and the performance of the KatoKatz technique in diagnosing Schistosoma mansoni and hookworm coinfections in rural Côte d'Ivoire. Parasitology 127, 525-531.

Brooker, S., Hotez, P. J. and Bundy, D. A. P. (2010). The global atlas of helminth infection: mapping the way forward in neglected tropical disease control. PLoS Neglected Tropical Diseases 4, e779.

Brooker, S. J., Pullan, R. L., Gitonga, C.W., Ashton, R.A., Kolaczinski, J. H., Kabatereine, N. B. and Snow, R. W. (2012). Plasmodium-helminth coinfection and its sources of heterogeneity across East Africa. Fournal of Infectious Diseases 205, 841-852.

Colley, D. G., Binder, S., Campbell, C., King, C. H., Tchuem Tchuenté, L.-A., N'Goran, E. K., Erko, B., Karanja, D. M., Kabatereine, N. B., van Lieshout, L. and Rathbun, S. (2013). A fivecountry evaluation of a point-of-care circulating cathodic antigen urine assay for the prevalence of Schistosoma mansoni. American fournal of Tropical Medicine and Hygiene 88, 426-432.

Cringoli, G., Rinaldi, L., Maurelli, M.P. and Utzinger, J. (2010) FLOTAC: new multivalent techniques for qualitative and quantitative copromicroscopic diagnosis of parasites in animals and humans. Nature Protocols 5, 503-515.

Danso-Appiah, A., Olliaro, P. L., Donegan, S., Sinclair, D. and Utzinger, J. (2013). Drugs for treating Schistosoma mansoni infection. Cochrane Database Systematic Reviews 2, CD000528. 
Engels, D., Sinzinkayo, E. and Gryseels, B. (1996). Day-to-day egg count fluctuation in Schistosoma mansoni infection and its operational implications. American fournal of Tropical Medicine and Hygiene 54, 319-324

Engels, D., Sinzinkayo, E., de Vlas, S. J. and Gryseels, B. (1997). Intraspecimen fecal egg count variation in Schistosoma mansoni infection. American Fournal of Tropical Medicine and Hygiene 57, 571-577.

Glinz, D., Silué, K. D., Knopp, S., Lohourignon, K. L., Yao, P. K., Steinmann, P., Rinaldi, L., Cringoli, G., N'Goran, E. K. and Utzinger, J. (2010). Comparing diagnostic accuracy of Kato-Katz, Koga agar plate, ether concentration, and FLOTAC for Schistosoma mansoni and soil-transmitted helminths. PLoS Neglected Tropical Diseases 4, e754.

Hotez, P. J., Molyneux, D. H., Fenwick, A., Kumaresan, J., Ehrlich Sachs, S., Sachs, J. D. and Savioli, L. (2007). Control of neglected tropical diseases. New England Fournal of Medicine 357, 1018-1027.

Humphries, D., Mosites, E., Otchere, J., Twum, W. A., Woo, L., Jones-Sanpei, H., Harrison, L. M., Bungiro, R. D., Benham-Pyle, B., Bimi, L., Edoh, D., Bosompem, K., Wilson, M. and Cappello, M. (2011). Epidemiology of hookworm infection in Kintampo North Municipality, Ghana: patterns of malaria coinfection, anemia, and albendazole treatment failure. American Fournal of Tropical Medicine and Hygiene 84, 792-800.

Hürlimann, E., Schur, N., Boutsika, K., Stensgaard, A.-S., Laserna de Himpsl, M., Ziegelbauer, K., Laizer, N., Camenzind, L., Di Pasquale, A., Ekpo, U.F., Simoonga, C., Mushinge, G., Saamak, C. F. L., Utzinger, J., Kristensen, T. K. and Vounatsou, P. (2011). Toward an open-access global database for mapping, control, and surveillance of neglected tropical diseases. PLoS Neglected Tropical Disease 5, e1404

Jeandron, A., Abdyldaieva, G., Usubalieva, J., Ensink, J. H. J., Cox, J., Matthys, B., Rinaldi, L., Cringoli, G. and Utzinger, J. (2010). Accuracy of the Kato-Katz, adhesive tape and FLOTAC techniques for helminth diagnosis among children in Kyrgyzstan. Acta Tropica 116, 185-192.

Katz, N., Chaves, A. and Pellegrino, J. (1972). A simple device for quantitative stool thick-smear technique in schistosomiasis mansoni. Revista do Instituto de Medicina Tropical São Paulo 14, 397-400.

Keiser, J. and Utzinger, J. (2008). Efficacy of current drugs against soiltransmitted helminth infections: systematic review and meta-analysis. Fournal of American Medical Association 299, 1937-1948.

Knopp, S., Mgeni, A. F., Khamis, I. S., Steinmann, P., Stothard, J. R., Rollinson, D., Marti, H. and Utzinger, J. (2008). Diagnosis of soiltransmitted helminths in the era of preventive chemotherapy: effect of multiple stool sampling and use of different diagnostic techniques. PLoS Neglected Tropical Diseases 2, e331.

Knopp, S., Glinz, D., Rinaldi, L., Mohammed, K. A., N'Goran, E. K., Stothard, J. R., Marti, H., Cringoli, G., Rollinson, D. and Utzinger, J. (2009). FLOTAC: a promising technique for detecting helminth eggs in human feces. Transactions of the Royal Society of Tropical Medicine Hygiene 103, 1190-1194.

Knopp, S., Mohammed, K. A., Speich, B., Hattendorf, J., Khamis, I. S., Khamis, A. N., Stothard, J. R., Rollinson, D., Marti, H. and Utzinger, J. (2010). Albendazole and mebendazole administered alone or in combination with ivermectin against Trichuris trichiura: a randomized controlled trial. Clinical Infectious Diseases 51, 14201428 .

Knopp, S., Speich, B., Hattendorf, J., Rinaldi, L., Mohammed, K. A., Khamis, I.S., Mohamemed, A.S., Albonico, M., Rollinson, D., Marti, H., Cringoli, G. and Utzinger, J. (2011). Diagnostic accuracy of Kato-Katz and FLOTAC for assessing anthelmintic drug efficacy. PLoS Neglected Tropical Diseases 5, e 1036.

Knopp, S., Steinmann, P., Keiser, J. and Utzinger, J. (2012). Nematode infections: soil-transmitted helminths and trichinella. Infectious Disease Clinics North America 26, 341-358.

Krauth, S. J., Coulibaly, J. T., Knopp, S., Traoré, M., N'Goran, E. K. and Utzinger, J. (2012). An in-depth analysis of a piece of shit: distribution of Schistosoma mansoni and hookworm eggs in human stool. PLoS Neglected Tropical Diseases 6, e1969.

Levecke, B., De Wilde, N., Vandenhoute, E. and Vercruysse, J. (2009). Field validity and feasibility of four techniques for the detection of Trichuris in simians: a model for monitoring drug efficacy in public health? PLoS Neglected Tropical Diseases 3, e366.

Levecke, B., Rinaldi, L., Charlier, J., Maurelli, M.P., Morgoglione, M.E., Vercruysse, J. and Cringoli, G. (2011). Monitoring drug efficacy against gastrointestinal nematodes when faecal egg counts are low: do the analytic sensitivity and the formula matter? Parasitology Research 109, 953-957.
Levecke, B., Rinaldi, L., Charlier, J., Maurelli, M.P., Bosco, A., Vercruysse, J. and Cringoli, G. (2012). The precision and accuracy of faecal egg count reduction test results in cattle using McMaster, CornellWisconsin and FLOTAC egg counting methods. Veterinary Parasitology 188, 194-199.

McCarthy, J. S., Lustigman, S., Yang, G. J., Barakat, R. M., Garcia, H. H., Sripa, B., Willingham, A.L., Prichard, R. K. and Basáñez, M. G. (2012). A research agenda for helminth diseases of humans: diagnostics for control and elimination programmes. PLoS Neglected Tropical Diseases 6, e1601.

Mekonnen, Z., Meka, S., Ayana, M., Bogers, J., Vercruysse, J. and Levecke, B. (2013). Comparison of individual and pooled stool samples for the assessment of soil-transmitted helminth infection intensity and drug efficacy. PLoS Neglected Tropical Diseases 7, e2189.

Montresor, A. (2011). Cure rate is not a valid indicator for assessing drug efficacy and impact of preventive chemotherapy interventions against schistosomiasis and soil-transmitted helminthiasis. Transactions of the Royal Society of Tropical Medicine Hygiene 105, 361-363.

Montresor, A., Engels, D., Chitsulo, L., Gabrielli, A., Albonico, M., Savioli, L. and Lammie, P. (2011). The appropriate indicator should be used to assess treatment failure in STH infections. American fournal of Tropical Medicine and Hygiene 85, 579-580.

NTD Partner Website (2012). Uniting to Combat Neglected Tropical Diseases. Ending the Neglect and Reaching 2020 Goals. http://www. unitingtocombatntds.org.

Pullan, R. L. and Brooker, S. J. (2012). The global limits and population at risk of soil-transmitted helminth infections in 2010. Parasites and Vectors $\mathbf{5}, 81$.

Rollinson, D., Knopp, S., Levitz, S., Stothard, J. R., Tchuem Tchuenté, L.-A., Garba, A., Mohammed, K. A., Schur, N., Person, B., Colley, D. G. and Utzinger, J. (2013). Time to set the agenda for schistosomiasis elimination. Acta Tropica 128, 423-440.

Sinniah, B. (1982). Daily egg production of Ascaris lumbricoides: the distribution of eggs in the feces and the variability of egg counts. Parasitology 84, 167-175.

Sousa-Figueiredo, J. C., Betson, M., Atuhaire, A., Arinaitwe, M., Navaratnam, A.M.D., Kabatereine, N.B., Bickle, Q. and Stothard, J. R. (2012). Performance and safety of praziquantel for treatment of intestinal schistosomiasis in infants and preschool children. PLoS Neglected Tropical Diseases 6, e1864.

Speich, B., Knopp, S., Mohammed, K. A., Khamis, I. S., Rinaldi, L., Cringoli, G., Rollinson, D. and Utzinger, J. (2010). Comparative cost assessment of the Kato-Katz and FLOTAC techniques for soil-transmitted helminth diagnosis in epidemiological surveys. Parasites and Vectors 3, 71 Steinmann, P., Utzinger, J., Du, Z.W., Jiang, J. Y., Chen, J.X., Hattendorf, J., Zhou, H. and Zhou, X. N. (2011). Efficacy of singledose and triple-dose albendazole and mebendazole against soil-transmitted helminths and Taenia spp.: a randomized controlled trial. PLoS One 6, e25003.

Utzinger, J., Rinaldi, L., Lohourignon, L. K., Rohner, F., Zimmermann, M. B., Tschannen, A. B., N'Goran, E. K. and Cringoli, G. (2008). FLOTAC: a new sensitive technique for the diagnosis of hookworm infections in humans. Transactions of the Royal Society of Tropical Medicine and Hygiene 102, 84-90.

Utzinger, J., N'Goran, E. K., Caffrey, C. R. and Keiser, J. (2011). From innovation to application: social-ecological context, diagnostics, drugs and integrated control of schistosomiasis. Acta Tropica 120 (Suppl.), S121-S137.

Utzinger, J., Becker, S. L., Knopp, S., Blum, J., Neumayr, A.L., Keiser, J. and Hatz, C. F. (2012). Neglected tropical diseases: diagnosis, clinical management, treatment and control. Swiss Medical Weekly 142, w13727.

Vercruysse, J., Behnke, J.M., Albonico, M., Ame, S. M., Angebault, C., Bethony, J.M., Engels, D., Guillard, B., Nguyen, T. V., Kang, G., Katulla, D., Kotze, A. C., McCarthy, J. S. Mekonnen, Z., Montresor, A., Periago, M.V., Tchuem Tchuenté, L.-A., Dang, T. C., Zeynudin, A. and Levecke, B. (2011). Assessment of the anthelmintic efficacy of albendazole in school children in seven countries where soil-transmitted helminths are endemic. PLoS Neglected Tropical Diseases 5, e948.

Viechtbauer, W. (2010). Conducting meta-analyses in R with the metafor package. Fournal of Statistical Software 36, 1-48.

World Health Organization (1991). Basic Laboratory Methods in Medical Parasitology. World Health Organization, Geneva, Switzerland. World Health Organization (2006). Preventive Chemotherapy in Human Helminthiasis: Coordinated Use of Anthelminthic Drugs in Control Interventions: A Manual for Health Professionals and Programme Managers. World Health Organization, Geneva, Switzerland. 
World Health Organization (2010). First WHO Report on Neglected Tropical Diseases 2010: Working to Overcome the Global Impact of Neglected Tropical Diseases. World Health Organization, Geneva, Switzerland.

World Health Organization (2011). Helminth Control in School-Age Children: A Guide for Managers of Control Programmes, 2nd Edn. World Health Organization, Geneva, Switzerland.
World Health Organization (2013). Assessing the Efficacy of Anthelminthic Drugs against Schistosomiasis and Soil-Transmitted Helminthiasis. World Health Organization, Geneva, Switzerland.

Ye, X.P., Donnelly, C. A., Fu, Y. L. and Wu, Z.X. (1997). The nonrandomness of the distribution of Trichuris trichiura and Ascaris lumbricoides in feces and the effect of stirring fecal specimens. Tropical Medicine and International Health 2, 261-264. 